\title{
NOTE
}

\section{Variable fishing mortality and the possible commercial extinction of the eastern Baltic cod}

\author{
Niclas Jonzén ${ }^{1, *}$, Per Lundberg ${ }^{1}$, Massimiliano Cardinale $^{2}$, Fredrik Arrhenius ${ }^{2}$ \\ ${ }^{1}$ Department of Theoretical Ecology, Ecology Building, Lund University, 22362 Lund, Sweden \\ ${ }^{2}$ National Board of Fisheries, Institute of Marine Research, PO Box 4, 45321 Lysekil, Sweden
}

\begin{abstract}
The recent decline in the Baltic cod Gadus morhua L. has been accompanied by an increase in population variability. Small population size, poor recruitment, and high population variability may be factors contributing to their imminent (commercial) extinction. Here we show that variable harvest rate, rather than variable recruitment, is the plausible cause of the increased variance in Baltic cod stock size. This calls for a reconsideration of the role of harvesting as a driving force in exploited populations. The mean exploitation rate, and also the variance, ought to be taken into account in fisheries and other population management.
\end{abstract}

KEY WORDS: Harvest - Stochastic population dynamics . Density dependence $\cdot$ Fisheries management

Resale or republication not permitted without written consent of the publisher

In exploited fish populations, most of the variance in stock size is attributed to highly variable recruitment (Fogarty et al. 1991). Understanding the recruitment process and how it relates to stock size (i.e., the often sought for stock-recruitment functions) and to environmental stochasticity is of central importance to fisheries science and management (Fogarty et al. 1991, Walters \& Parma 1996). In many, if not most, exploited marine fish populations, fishing mortality is the other major force affecting stock size. Harvesting is very often thought of as a relatively constant disturbance over time, pushing down the mean population size unless there is complete density-dependent compensation (Boyce et al. 1999). In practice, harvest rate will vary and could be described by a beta distributed stochastic variable if, on average, a constant proportion is removed from the population over time (Lauck et al. 1998). The mean and variance of a beta distribution are determined by 2 parameters, $\alpha$ and $\beta$. If $\alpha$ and $\beta$ are equal, the probability density function is symmetric around 0.5 . For further details about the beta distribu-

\footnotetext{
*E-mail: niclas.jonzen@teorekol.lu.se
}

tion, see any textbook on probability theory. The lack of precision in attaining the target harvest rate may have several causes, but the question of how variable harvesting and recruitment act in concert with the deterministic (density-dependent) skeleton of population dynamics to produce the observed pattern has largely been ignored (Patterson 1999, Mangel 2000). This hints at the more general ecological problem of how environmental stochasticity translates into observable population dynamics.

In the Baltic Sea, there are 2 stocks of Baltic cod Gadus morhua L., one on either side of longitude $14^{\circ} 30^{\prime} \mathrm{E}$ (Bagge et al. 1994). The eastern stock has declined since the mid-1980s (Fig. 1) and its recruitment, which is also dependent on the rare occasions of salt-water inflow (Bagge et al. 1994), has been weak since 1989. However, inflow as such does not ensure good recruitment, rather a number of biotic factors-including spawning stock biomass and age structure-interact with environmental factors such as oxygen content and salinity (see, e.g., Kuikka et al. 1999, Vallin et al. 1999, Cardinale \& Arrhenius in press). In this paper, we will first demonstrate that not only has the Baltic cod declined to a very low level, but that the dramatic decline has been accompanied by an increasing variance in stock size. Second, we argue that the variable exploitation of this fish stock itself, rather than poor and variable recruitment, may be responsible for this pattern.

Methods. We have analysed commercial and research survey data from the eastern stock in ICES (the International Council for the Exploration of the Sea) subdivisions 25 to 32 (Anonymous 1998). One time series, independent of commercial fisheries, is the Swedish survey estimate of abundance. Here we call this abundance index $N_{t}$. Spawning stock biomass (SSB, thousands of tonnes) and fishing mortality $(F)$ are calculated by ICES using a Virtual Population Analysis (see, e.g., Hilborn \& Walters 1992; for details, 

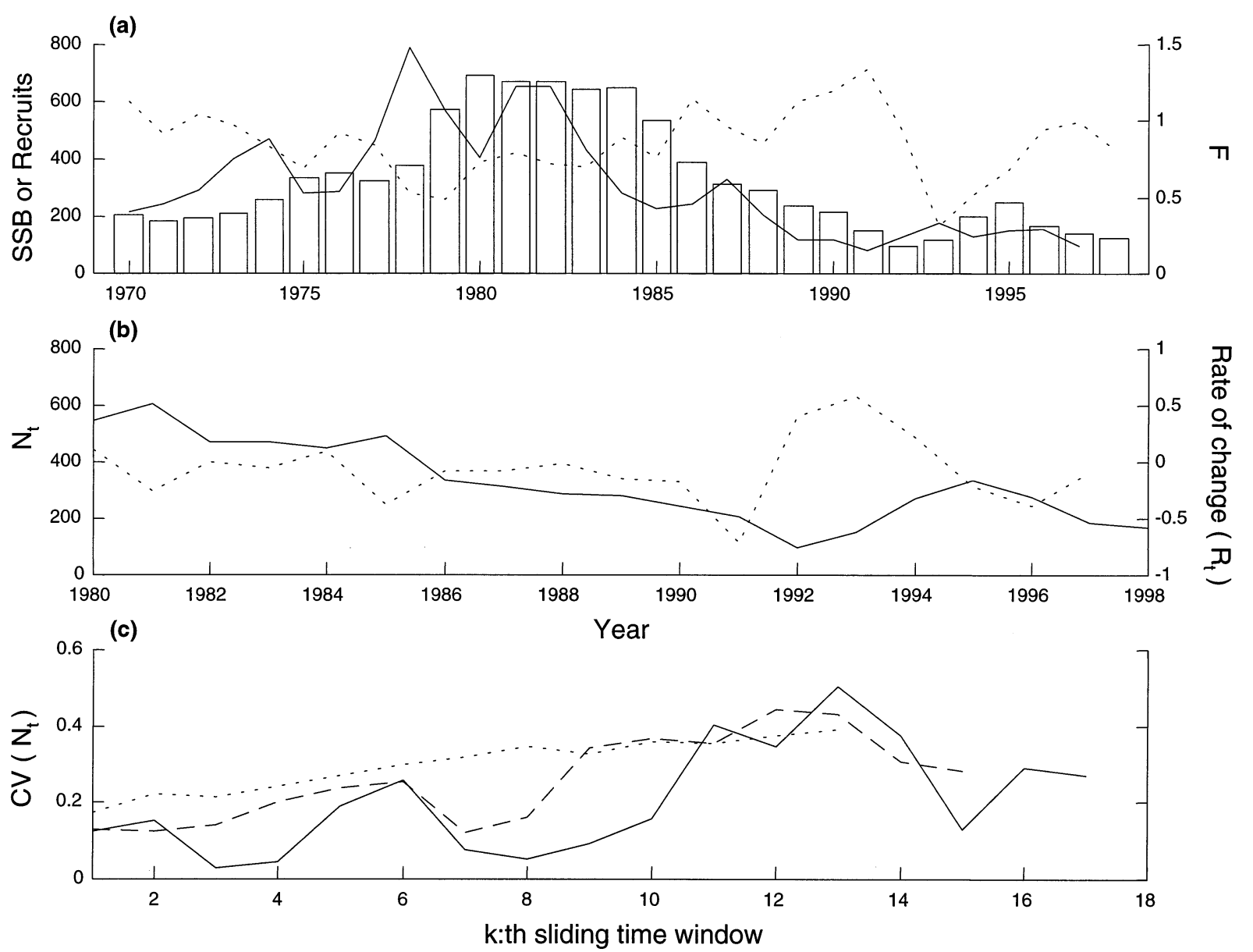

Fig. 1. Baltic cod stock size and recruitment. (a) Change in spawning stock biomass (SSB, bars), in thousands of tonnes, number of recruits at age 2 (in thousands, solid line) and the fishing mortality ( $F$, dotted line and right axis) over time. All numbers are calculated by ICES using a Virtual Population Analysis (Hilborn \& Walters 1992, Anonymous 1998). (b) Swedish survey index of abundance $\left(N_{t}\right.$, solid line) and the population rate of change $\left(R_{t}\right)$ over time (dotted line, right axis). (c) Change in coefficient of variation $(\mathrm{CV})$ of $N_{t}$ over time. $\mathrm{CV}$ was calculated in a 3 (solid line), 5 (dashed line) or 7 yr (dotted line) sliding (1 year at a time) time window covering the entire series

see Anonymous 1998) and the recruitment is the estimated number (in thousands) of $2 \mathrm{yr}$ cod at the beginning of the year (Anonymous 1998). Finally, landings (thousands of tonnes) refers to commercial catch. To simplify the analysis for a reader not familiar with traditional fisheries terms, we converted the $F$ to an annual harvest rate or fraction $(h)$ according to:

$$
h=1-\exp (-F)
$$

Direct and delayed density dependence were estimated by regressing the population rate of changedefined as $R_{t} \equiv \log _{\mathrm{e}}\left(N_{t+1} / N_{t}\right)$ - on $N_{t}$ and $N_{t-1}$ (partialling out the effect of $N_{t}$ ). This test, known as Turchin's test (Turchin 1990, Holyoak 1994), has a high detection rate of density dependence but may sometimes detect spurious correlation (Holyoak 1994). Hence, a negative correlation would not necessarily indicate density dependence (Royama 1992), but the absence implies no, or possibly weak, density dependence. We denote the regression coefficient corresponding to lag 1 and lag 2 by $a_{1}$ and $a_{2}$, respectively.

To demonstrate how the variance in abundance, recruitment and fishing mortality has changed over time, we used a sliding ( 1 year at a time) time window covering the entire series (Ranta et al. 1997). Before this analysis, data were detrended by first-order differencing (Chatfield 1999). The exact variance pattern is dependent on the length of the sliding time window (see examples below).

Finally, we regressed the estimated yearly landings on SSB for the entire time period to highlight how the harvest rate is related to biomass. This analysis was complemented by fitting a beta-distributed probability density function to the time series of annual harvest rate, resulting in an estimate of both the mean and the variance in harvest rate. 
Results and discussion. There were no significant regression coefficients when regressing the population rate of change on population density, suggesting no density dependence or possibly weak regulation. The regression coefficient at $a_{1}$ was $-0.26(95 \% \mathrm{CI}=$ $\left.-0.64-0.13 ; \mathrm{R}^{2}=0.15 ; \mathrm{p}=0.12\right)$, and adding a second lag did not significantly reduce the unexplained variance $\left(a_{1}=-0.039 ; 95 \% \mathrm{CI}=-0.66-0.59 ; a_{2}=-0.27\right.$; $\left.95 \% \mathrm{CI}=-0.89-0.35 ; \mathrm{R}^{2}=0.22 ; \mathrm{p}=0.17\right)$. This is not surprising considering that the population is pushed down far below historical levels (Fig. 1). By definition, the rate of change $\left(R_{t}\right)$ is potentially a function of not only past densities, but also of recruitment and mortality not captured by including past densities. We find a weak correlation between recruitment and $R_{t}(\mathrm{r}=0.14)$ but a 4 to 5 times stronger correlation between fishing mortality $(F)$ and $R_{t}(\mathrm{r}=-0.62)$. Hence, harvesting seems to be the dominating factor for the population growth rate while density dependence and poor recruitment play only a minor role.
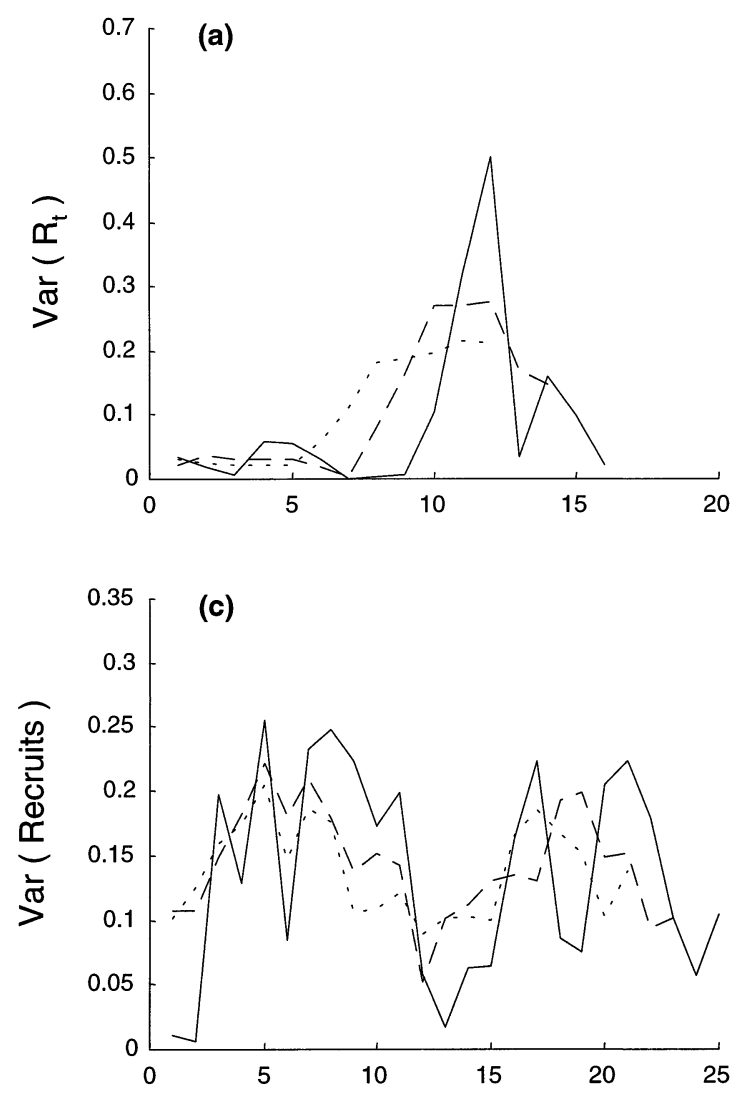

The survey index of stock size $\left(N_{t}\right)$ also shows that the coefficient of variation-a proxy for extinction risk-has increased over time (Fig. 1c). Hence, we have a declining population at low density fluctuating with increasing amplitude relative to the mean level. Since the growth is close to exponential-(i.e. no density dependence), the population is unable to compensate for losses, a hazardous situation from a management and conservation point of view. To argue that the stock has compensated for losses in the past is not necessarily relevant, due to a temporal change in biotic (e.g., age composition) as well as abiotic factors (Kuikka et al. 1999).

It is well documented that recruitment, and therefore total stock abundance, may be driven by long-term environmental changes in marine systems (Steele 1985, Fogarty et al. 1991, Walters \& Parma 1996). We could not, however, find any association between recruitment variability and the variability in SSB in the declining Baltic cod stock (Fig. 2). This relates to the
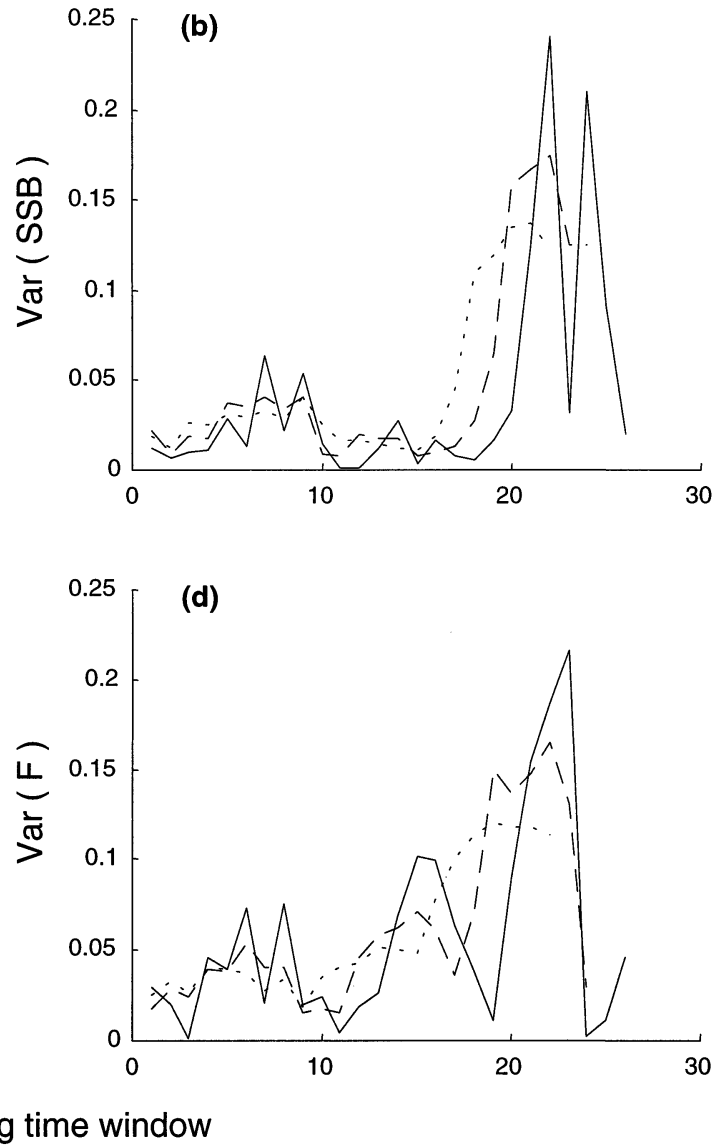

Fig. 2. Change in population, recruitment, and fishing mortality variability over time. In all 4 cases, the variance of the time series was calculated in a 3 (solid line), 5 (dashed line) or $7 \mathrm{yr}$ (dotted line) sliding (1 year at a time) time window covering the entire series. All series were detrended by first-order differencing and SSB and $N_{t}$ were $\log _{\mathrm{e}}$-transformed before the detrending. (a) Variance of $R_{t}\left[=\log _{\mathrm{e}}\left(N_{t+1}\right)-\log _{\mathrm{e}}\left(N_{t}\right)\right]$. (b) Variance of SSB. (c) Variance in recruitment at Age 2. (d) Variance in fishing mortality. (a) \& (b) show that the variability in estimated stock size ( $N_{t}$ and SSB) has increased over time, and so has the variability in fishing mortality. Recruitment variability has, however, remained rather constant 
previous finding that variation in stock size can rarely account for the observed variation in recruitment (see, e.g., Rijnsdorp et al. 1991, Marshall et al. 1998, Cardinale \& Arrhenius 2000)

Another factor causing the increased variability in stock size is a rise in harvest rate variability. There are strong theoretical indications that a stochastic disturbance (e.g., harvest with a constant target fraction) may generate a substantial increase in the variability of population size (Kaitala et al. 1996). There is likewise strong empirical support for the assumption of a constant target harvest rate in the Baltic cod fisheries. We regressed the estimated yearly landings on SSB for the entire time period and found a strong linear relationship (Fig. 3). The slope of this regression line (0.54) is the average (target) harvest rate. This finding was substantiated by fitting a beta distribution to the ICES data on fishing mortality and the estimated mean har- vest rate was 0.56 , remarkably close to the landings versus SSB estimate. Interestingly, the variance in harvest rate increased over time such that this change very closely matches the increase in variance of stock size (Fig. 2). Hence, it seems reasonable that the recent increase in variance of the Baltic cod stock is explained by variable fishing effort, rather than variable oceanographic conditions mirrored in recruitment. Note, however, that the observed increase in variance in harvest rate as well as SSB is probably affected by false reports in the early 1990s (Anonymous 1999).

Previous work on variable (or rather uncertain) harvest rate has focused on the probability of a defined management success for different coefficients of variation in harvest rate distribution (Lauck et al. 1998, Patterson 1999, Mangel 2000). Our approach is different and more mechanistic. Instead of finding appropriate management strategies in the face of uncertainty

(a)

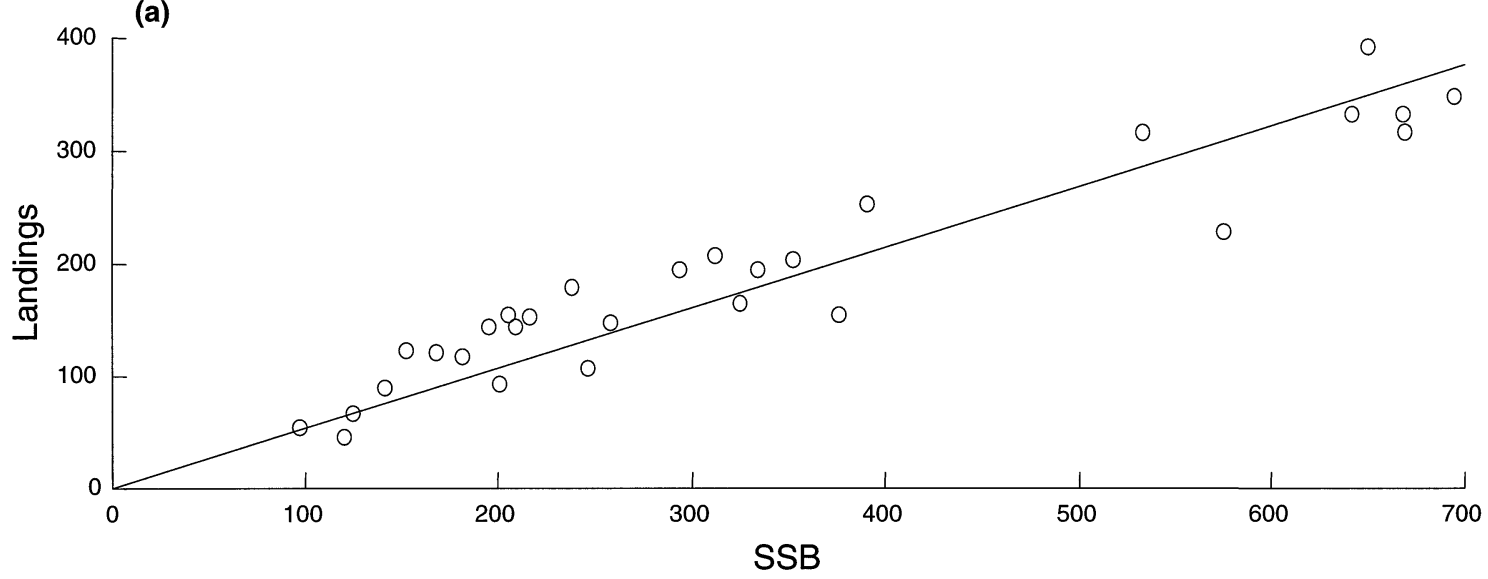

(b)

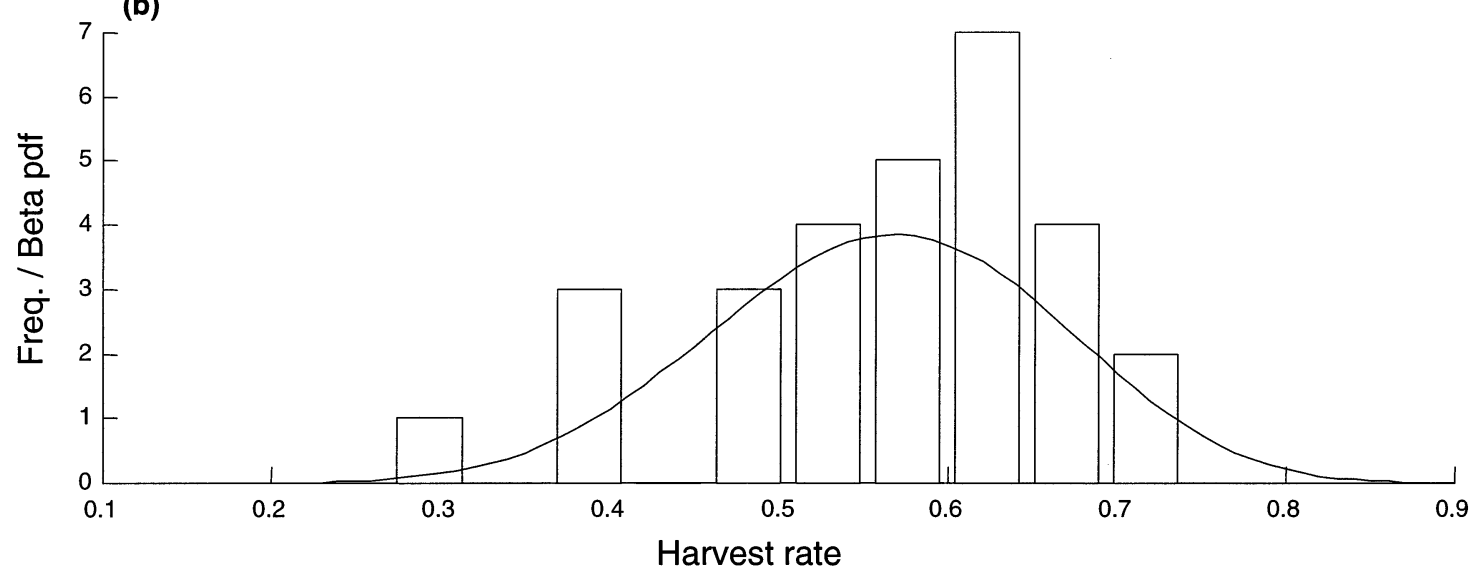

Fig. 3. Landings and distribution of harvest rate in the Baltic cod. (a) Commercial landings 1970 to 1998 as a function of the SSB. Landings and SSB are given in thousands of tonnes. Linear regression: slope $=0.54, \mathrm{R}^{2}=0.87$. (b) Frequency distribution of harvest rate 1970 to 1998 (bars) and the fitted beta probability density function (pdf, solid line). The maximum likelihood estimated parameters of the beta distribution, $\alpha=13.1$ (95\% CI 7.3 to 18.9 ) and $\beta=10.2$ (95\% CI 4.9 to 15.5), correspond to mean $=0.56$ and variance $=0.001$ 
(including variable harvest rate), we have tried to reduce uncertainty by disentangling the effects of population density, environmental variation and harvesting. This approach has turned out to be successful in population ecology (Ranta et al. 1999) and should also be promising in natural resource management, including fisheries (Stenseth et al. 1999). In fact, we strongly believe that fisheries management would benefit from an increased understanding of the synergistic effect of endogenous (e.g., density-dependent recruitment) and exogenous (e.g., harvesting) components of population dynamics. This study clearly demonstrates how harvest may work as stochastic forcing and actually dictate the fluctuations if the endogenous dynamics are close to exponential growth.

We have, however, completely ignored observation uncertainty, which of course is present in the survey data as well as in the reported catch data. There are 2 possible effects of observation uncertainty in this study. First, Walters \& Ludwig (1987) have shown that observation uncertainty results in the overestimation of the amount of density dependence if the regulation is weak. Since we did not find any density dependence and the assumption of weak regulation seems reasonable, this should not be a problem here. Second, when a population drops to low density, the observation uncertainty may increase due to increased sampling variance. That could possibly explain the variance patterns found. However, the survey has been more standardised in recent years (B. Sjöstrand pers. comm.). Hence, the net effect of better sampling of a stock at low density is not yet clear. Furthermore, the strong correlation between fishing mortality and population growth rate is reasonable considering the absence of density dependence and the high fishing mortality.

On average, more than $50 \%$ of the eastern Baltic cod stock is harvested every year, which is above the recommendations for sustainable exploitation (about $45 \%$ ) given by the ICES Advisory Committee on Fishery Management (ACFM) (Anonymous 2000). However, the variation in harvest rate is striking, and our new findings suggest that not only the mean harvest rate is far too high, but also that the (increased) variability in harvest rate may be of profound importance for population persistence. If no action is taken to reverse the negative trend and dampen the fluctuations, one would expect the Baltic cod to tread the same route as the Northern cod off Newfoundland and Labrador (Hutchings \& Myers 1994, Myers et al. 1997): the route to commercial extinction.

Acknowledgements. This study was supported by grants from The Swedish Natural Science Research Council and the Swedish Research Council for Forestry and Agriculture. J. Ripa made invaluable comments and suggestions.

\section{LITERATURE CITED}

Anonymous (1998) Report of the Baltic Fisheries Assessment Working Group. ICES CM 1998/ACFM:16

Anonymous (1999) Stocks in the Baltic. Extract of the report of the Advisory Committee on Fishery Management No. 6. ICES May 1999

Anonymous (2000) Report of the Baltic Fisheries Assessment Working Group. ICES CM 2000/ACFM:14

Bagge O, Thurow F, Steffenses E, Bay J (1994) The Baltic cod. Dana 10:1-28

Boyce MS, Sinclair ARE, White GC (1999) Seasonal compensation of predation and harvesting. Oikos 87:419-426

Cardinale M, Arrhenius F (2000) The relationship between stock and recruitment: are the assumptions valid? Mar Ecol Prog Ser 196:305-309

Cardinale M, Arrhenius F (in press) The influence of stock structure and environmental conditions on the recruitment process of Baltic cod using Generalized Additive Model (GAM). Can J Fish Aquat Sci

Chatfield C (1999) The analysis of time series: an introduction, 5th edn. Chapman \& Hall, Boca Raton

Fogarty MJ, Sissenwine MP, Cohen EB (1991) Recruitment variability and the dynamics of exploited marine populations. Trends Ecol Evol 6:241-246

Hilborn R, Walters CJ (1992) Quantitative fisheries stock assessment: choice, dynamics \& uncertainty. Chapman \& Hall, New York

Holyoak M (1994) Identifying delayed density dependence in time-series data. Oikos 70:296-304

Hutchings JA, Myers RA (1994) What can be learned from the collapse of a renewable resource? Atlantic cod, Gadus morhua, of Newfoundland and Labrador. Can J Fish Aquat Sci 51:2126-2146

Kaitala V, Ranta E, Lindström J (1996) Cyclic population dynamics and random perturbations. J Anim Ecol 65: 249-251

Kuikka S, Hildén M, Gislason H, Hansson S, Sparholt H, Varis O (1999) Modeling environmentally driven uncertainties in Baltic cod (Gadus morhua) management by Bayesian influence diagrams. Can J Fish Aquat Sci 56:629-641

Lauck T, Clark CW, Mangel M, Munro GR (1998) Implementing the precautionary principle in fisheries management through marine reserves. Ecol Appl 8(Suppl):72-78

Mangel M (2000) On the fraction of habitat allocated to marine reserves. Ecol Lett 3:15-22

Marshall CT, Kjesbu OS, Yaragina NA, Solemdal P, Ulltang $\varnothing$ (1998) Is spawner biomass a sensitive measure of the reproductive and recruitment potential of Northeast Arctic cod? Can J Fish Aquat Sci 55:1766-1783

Myers RA, Hutchings JA, Barrowman NJ (1997) Why do fish stocks collapse? The example of cod in Atlantic Canada. Ecol Appl 7:91-106

Patterson KR (1999) Evaluating uncertainty in harvest control law catches using Bayesian Markov chain Monte Carlo virtual population analysis with adaptive rejection sampling and including structural uncertainty. Can J Fish Aquat Sci 56:208-221

Ranta E, Kaitala V, Lundberg P (1997) The spatial dimension in population fluctuations. Science 278:1621-1623

Ranta E, Kaitala V, Lundberg P (1999) A tale of big games and small bugs. Science 285:1022-1023

Rijnsdorp AD, Daan N, van Beek FA, Heesen HJL (1991) Reproductive variability in North Sea plaice, sole and cod. J Cons Int Explor Mer 47:352-375

Royama T (1992) Analytical population dynamics. Chapman \& Hall, London 
Steele JH (1985) A comparison of terrestrial and marine ecological systems. Nature 313:355-358

Stenseth NC, Bjørnstad ON, Falck W, Fromentin JM, Gjøsæter J, Gray JS (1999) Dynamics of coastal cod populations: intra- and intercohort density dependence and stochastic processes. Proc R Soc Lond B 266: 1645-1654

Turchin P (1990) Rarity of density dependence or population regulation with lags? Nature 344:660-663

Editorial responsibility: Otto Kinne (Editor),

Oldendorf/Luhe, Germany
Vallin L, Nissling A, Westin L (1999) Potential factors influencing reproductive success of Baltic cod, Gadus morhua: a review. Ambio 28:92-99

Walters C, Ludwig D (1987) Effects of measurement errors on the assessment of stock-recruitment relationships. Can J Fish Aquat Sci 38:704-710

Walters C, Parma AM (1996) Fixed exploitation rate strategies for coping with effects of climate change. Can J Fish Aquat Sci 53:148-158

Submitted: July 24, 2000; Accepted: October 18, 2000 Proofs received from author(s): December 19, 2000 